\title{
CIUDADES Y VILLAS EN EL REINO DE PORTUGAL EN LA BAJA EDAD MEDIA. LOS FACTORES POLÍTICO Y JURISDICCIONAL COMO CRITERIOS DE JERARQUIZACIÓN*
}

\author{
CITIES AND TOWNS IN THE PORTUGUESE KINGDOM \\ IN THE LATE MIDDLE AGES. THE POLITICAL AND JURISDICTIONAL \\ FACTORS AS HIERARCHIZATION CRITERIA
}

\author{
AdELAIDE Millán dA COSTA \\ Universidade Aberta. Instituto de Estudos Medievais - FCSH/NOVA \\ http://orcid.org/0000-0001-9335-9386
}

\begin{abstract}
Resumen: En este artículo se plantean las competencias políticas de las ciudades y villas portuguesas en los siglos XV e inicios del XVI, conjugadas con su definición o evolución jurisdiccional. Así, el factor político corresponde al enfoque de observación de una posible jerarquía de las comunidades urbanas -de acuerdo con ciertos criterios de delimitación del grupo y, en su interior, del rango asignado a cada una-; mientras que el elemento jurisdiccional es la variable en función de la cual vamos a profundizar en el tema. Se asume la perspectiva de sistematizar el conocimiento ya producido y de presentar nuevos datos, problemas e interpretaciones, estrategia que creemos pueda ser productiva en el contexto de este monográfico, pues hace posible la comparación con realidades de otros reinos. Palabras clave: Edad Media; ciudades y villas; comunicación política; jerarquía urbana; cortes.
\end{abstract}

Abstract: In this article we propose an analysis of the political competences of Portuguese cities and towns in the $15^{\text {th }}$ and early $16^{\text {th }}$ centuries, combined with their definition or jurisdictional evolution. In this context, the political factor reflects an approach that analyses the existence of a possible hierarchy of urban communities -according to certain delimitation criteria for the group as a whole and, within it, of the rank assigned to each- whereas the jurisdictional element is the variable which will enable us to deal with the subject in greater depth. We adopt a perspective that involves systematizing already produced knowledge and presenting new data, problems and interpretations; we believe that this strategy can be productive in the context of this monograph, making comparison with the situation existing in other kingdoms possible.

Keywords: Middle Ages; cities and towns; political communication; urban hierarchy; parliament.

\section{SUMARIO}

1. Introducción: objeto de estudio y perspectiva de análisis.- 2. La integración urbana en el sistema político medieval portugués.- 3. Las ciudades y villas señoriales en cortes.- 4. Conclusión.- 5. Fuentes y bibliografía citada.

\footnotetext{
*Este trabajo se ha realizado en el marco del proyecto HAR2013-44014-P, financiado por el Ministerio de Economía y Competitividad y dirigido por María Asenjo González, de la Universidad Complutense de Madrid. Agradezco a la Profesora María Asenjo González la revisión lingüística del texto.

Cómo citar este artículo: Costa, Adelaide Millán da, (2018), Ciudades y villas en el reino de Portugal en la Baja Edad Media. Los factores político y jurisdiccional como criterios de jerarquización, "Anuario de Estudios Medievales" 48/1, pp. 25-47. https://doi.org/10.3989/aem.2018.48.1.01

Copyright: (C) 2018 CSIC. Este es un artículo de acceso abierto distribuido bajo los términos de la licencia de uso y distribución Creative Commons Reconocimiento 4.0 Internacional (CC BY 4.0).
} 


\section{INTRODUCCIÓN: OBJETO DE ESTUDIO Y PERSPECTIVA DE ANÁLISIS}

En el ámbito del presente dosier temático sobre la jerarquización urbana en la Baja Edad Media, decidimos centrar nuestro análisis en el marco del reino de Portugal y adoptar el enfoque en los aspectos políticos ${ }^{1}$.

Este planteamiento inicial -la categorización política de las ciudades y villas a la escala de un reino-implica, o bien el previo desarrollo de trabajos historiográficos con base en los cuales se pueda hacer una síntesis, o bien la preexistencia de un cuadro de referencia que clasifique las comunidades. En cuanto a la primera condición de soporte del estudio, pese al gran avance de la investigación sobre ciudades y villas medievales realiza desde los años ochenta del siglo pasado, aún no se ha organizado un plan de examen sistemático de las competencias políticas de cada centro urbano portugués a lo largo del tiempo ${ }^{2}$. Sin embargo, existe, y fue utilizada innumerables veces por los medievalistas portugueses, una representación gráfica que permite concretar la segunda hipótesis. Se trata de un dibujo incluido en un libro de registros de un secretario del rey, fechado en 1481, que indica la posición relativa de los delegados de cada comunidad en los bancos de la ceremonia inaugural de las cortes ${ }^{3}$.

La dificultad para realizar una síntesis válida, debido a la escasez de trabajos monográficos ${ }^{4}$, sugería retomar como alternativa el estudio de la referida representación gráfica, ya profusamente analizada. De hecho, ¿qué mejor campo de observación de las categorías políticas de la sociedad corporativa se puede elegir que su propia traducción en el escenario del parlamento medieval ${ }^{5}$ ?

No obstante, el riesgo de sobrevalorar un solo factor -el político simbólico- sería la inmediata objeción a este enunciado, ya que, si hubiéramos

\footnotetext{
${ }^{1}$ Por consiguiente, no vamos a analizar la jerarquización de acuerdo con otros criterios como los de centralidad. Véase Boissellier 2009.

${ }^{2}$ Dicho avance de la investigación, iniciado por Marques 1988a, 1988b, ha permitido la elaboración de monografías científicas sobre las ciudades y villas medievales y, como resultado, tenemos hoy un conocimiento extenso, pero con algunas lagunas cronológicas, territoriales y temáticas, del panorama urbano bajomedieval del reino portugués. No se ha prestado especial atención a la dimensión política, pese a algunos trabajos desarrollados. Consúltese la última reseña sobre esta evolución historiográfica en Andrade, Costa 2011, pp. 283-301. Además, véase la síntesis sobre la historiografía de los municipios en Coelho 2011, pp. 209-230, que muestra un filón de estudios por desarrollar.

${ }^{3}$ Cf. Chaves, Livro de Apontamentos 1438-1489 ed. Anastásia Mestrinho Salgado e Abílio José Salgado, pp. 117-118.

${ }^{4}$ Referentes al estudio de las competencias políticas de las ciudades y villas, y no a otras temáticas urbanas.

${ }^{5}$ Adoptamos el concepto de parlamento medieval definido por Armindo de Sousa y fundamentado en numerosos trabajos que aquí se citan: Sousa 1985, 1989, 1989a, 1990, 1990a, 1990b.
} 
logrado desarrollar la hipótesis inicial del trabajo, indagaríamos el posicionamiento relativo de las comunidades territoriales, en el marco del sistema político, conectando un conjunto complejo de elementos de distinta naturaleza. Aludimos a cuestiones sobre: (I) la definición y evolución jurisdiccional de la ciudad o villa; (II) sus atribuciones político-administrativas en el ámbito del reino, así como a su propia localización en el circuito geográfico privilegiado de la corte y la correspondiente articulación entre centros, periferias o zonas de influencia; (III) los nexos de vínculos familiares y clientelares en los cuales participaban sus elites dirigentes ${ }^{6}$. También valoraríamos la influencia de las coyunturas, que consiguieron cambiar los equilibrios establecidos.

A la posible restricción del enfoque, se uniría el problema de la pertinencia del estudio- ¿Qué podría añadirse a la interpretación de esa jerarquía de las comunidades urbanas -y de todos los órdenes del reino-alrededor de la cabeza del sistema, el rey?

Son varios los autores que alertan de los peligros interpretativos de tomar al pie de la letra el rango atribuido a las ciudades y villas, a partir de la disposición de los asientos fijados para sus delegados en cortes. Sin afirmar que la posición relativa de los representantes de los concejos en este espacio mimetiza la jerarquía política, defendemos la validez de recurrir a esa fuente para sacar conclusiones sobre la realidad subyacente. De hecho, la disposición de los actores concejiles en ese ambiente no fue estática ${ }^{7}$, facultando una descripción de las dinámicas de cambio.

Además, en este artículo, esa representación funciona como el mero escenario donde se va a examinar un aspecto muy concreto. Nos proponemos reflexionar sobre la posición relativa que los delegados de cada comunidad ocupaban en la ceremonia, asociada a los cambios surgidos en el dominio jurisdiccional de los concejos. Un enfoque que aún no ha sido desarrollado de forma sistemática y que creemos permitirá avanzar en el análisis de las relaciones surgidas entre la competencia política de las comunidades y su definición jurisdiccional.

Si quisiéramos afiliar nuestro trabajo en un área de investigación historiográfica, sería la del estudio del sistema político y de sus actores, privilegiando la comunicación política entre los concejos y la corona establecida en cortes $^{8}$. Así, intentaremos captar el sistema político en acción.

\footnotetext{
${ }^{6}$ Seguimos la tipología presentada por Costa 1999, pp. 245 y ss.

${ }^{7}$ Aunque ese informe esté sustentado en datos tardíos. Cf. Sousa 1990, vol. I, pp. 190-194; Costa 2014, pp. 63-70; Cardim 1998, pp. 65 y ss. (este último para el siglo XVII).

${ }^{8}$ Véase un análisis exhaustivo sobre la aplicabilidad del concepto de cultura política como categoría de interpretación en Carrasco 2016, pp. 31-38; Costa 2013, pp. 9-29 (y bibliografía citada en los dos títulos).
} 
A continuación, trazaremos un breve estado de la cuestión sobre la fiabilidad del análisis a partir de un recurso de imagen cristalizada, intentando evaluar la diferencia entre la representación y lo que pudiera haber sido la realidad y, finalmente, abordaremos la presencia de los centros urbanos señoriales en el parlamento.

\section{LA INTEGRACIÓN URBANA EN EL SISTEMA POLÍTICO MEDIEVAL PORTUGUÉS}

Según el derecho positivo regio, confirmado en innumerables casos por la documentación, todas las colectividades con algún grado de autonomía y organización reconocida -o sea todos los concejos- tienen capacidad para entablar un diálogo con los otros miembros del sistema político ${ }^{9}$, ya sea la corona, los señores u otros concejos. Esta facultad de comunicación, traducida en forma de protesta, solicitud, simple colaboración o informe, correspondería al nivel básico de ejercicio de competencias políticas de las comunidades territoriales, equivaliendo al mínimo denominador común de integración en un cuerpo que las transciende.

Un grado superior de competencia política de los concejos es el que atañe a la capacidad simultánea de hacer oír su voz e intervenir de modo concertado y como grupo de presión, que representa un orden del reino, en la toma de decisiones, en el contexto de las cortes. Esta aptitud deriva de la admisión, por la corona, de algunas ciudades y villas en el círculo de las comunidades territoriales que actuarían en nombre de todas ${ }^{10}$.

Los dos párrafos precedentes, en apariencia inocuos, en lo que a la claridad del mensaje transmitido concierne, motivan dudas cuando se pretende identificar las ciudades y villas que se incluyen en el primer o segundo grados de participación política.

Centrémonos en la observación del cuadro de la ceremonia de apertura de cortes, abajo reproducido, como fuente para plantear el tema.

\footnotetext{
${ }^{9}$ Esta capacidad estaba reconocida en las Ordenações Afonsinas ed. Mário Júlio de Almeida Costa e Eduardo Borges Nunes y garantizada a todas las comunidades territoriales por pequeñas que fuesen. $C f$. Coelho 2011, pp. 209-230.

${ }^{10}$ Sobre el proceso de convocación y también de constitución de cada asamblea, véase Sousa 1990 , vol. I, pp. 111 y ss.
} 
Cuadro 1. Ciudades y villas con asiento en la ceremonia de apertura de cortes (1481) ${ }^{11}$

\begin{tabular}{|c|l|}
\hline BANCO & \multicolumn{1}{|c|}{ CIUDADES Y VILLAS } \\
\hline 1 & Lisboa, Coimbra, Évora, Santarém, Porto \\
\hline 2 & Braga, Lamego Viseu, Silves, Guarda \\
\hline 3 & Elvas, Guimarães, Beja, Tavira, Leiria \\
\hline 4 & Estremoz, Montemor-o-Novo, Tomar, Covilhã, Bragança \\
\hline 5 & Vila Real, Moura, Faro, Montemor-o-Velho, Ponte de Lima \\
\hline 6 & Alenquer, Castelo Branco, Torres Novas, Aveiro, Sintra \\
\hline 7 & $\begin{array}{l}\text { Óbidos, Setúbal, Torres Vedras, Alcácer do Sal, Portalegre, Almada } \\
\text { e Nisa }\end{array}$ \\
\hline 8 & Serpa, Mourão, Lagos, Trancoso, Olivença \\
\hline 9 & Pinhel, Abrantes, Arronches, Loulé, Avis \\
\hline 10 & Valença, Monção, Freixo de espada à Cinta, Alegrete, Alter do Chão \\
\hline 11 & Penamacor, Marvão, Castelo de Vide, Sertã, Castelo Rodrigo \\
\hline 12 & Monforte, Veiros, Fronteira, Campo Maior, Crato \\
\hline 13 & Viana do Castelo, Palmela, Castro Marim, Cabeço de Vide Moncorvo \\
\hline 14 & Monsanto, Garvão, Coruche, Panoias, Miranda do Douro \\
\hline 15 & Albufeira, Borba, Ourique, Portel, Arraiolos \\
\hline 16 & Vila Viçosa, Penela, Monsaraz \\
\hline
\end{tabular}

Esta representación plantea cuestiones de dos naturalezas.

La primera, concierne a la relación que el cuadro mantiene con lo que habría sido la realidad externa. Es decir, ¿esta clasificación funcionaría en circuito cerrado, cristalizando una imagen datada, inmune a eventuales cambios en el estatus político (no desvinculada de los aspectos económicos, administrativos, jurisdiccionales) de los centros urbanos?

Varios fueron los autores que se acercaron al tema y, por eso, nos limitamos aquí a glosar el conocimiento ya producido, intentando acrecentar algunas reflexiones. Ciertamente, no existe información continuada en el tiempo que nos permita un análisis sustentado de los lugares asignados a los delegados de las comunidades, provocando una notoria ausencia de datos con

${ }^{11}$ Este cuadro fue presentado por Sousa 1990, vol. I, p. 192, y no se limita a reproducir la planta del libro de apuntamientos, sino que jerarquiza las ciudades y villas en función de la importancia del asiento: así, en el primer banco la representación era: Porto (5. . lugar), Évora

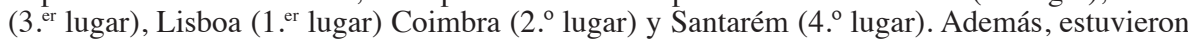
presentes en la ceremonia y están indicados en la planta, pero sin lugar sentado, los delegados de Ourém, Porto de Mós, Pombal, Santiago do Cacém, Vila Nova de Cerveira, Viana de Alvito e Atouguia. Chaves, Livro de Apontamentos 1438-1489 ed. Anastásia Mestrinho Salgado e Abílio José Salgado, pp. 117-118; Sousa 1990, vol. I, p. 193. 
anterioridad a finales del Cuatrocientos. Pero, además de la imagen de $1481^{12}$, existen otras para $1535^{13}, 1619$ y fechas posteriores ${ }^{14}, \mathrm{y}$ es posible reconstituir la organización del espacio del acto inaugural de las cortes de $1502^{15}$.

De los variados estudios y comparaciones de informes, los autores concluyen que el cuadro sería estable, aunque fuese permeable a cambios de diferentes tipos; como la alteración del estatuto político de un centro urbano (de villa a villa notable ${ }^{16}$ o de villa notable a ciudad ${ }^{17}$ ) lo que implicaba un cambio en la ocupación de los bancos, aunque no de inmediato. Había cierta tendencia a la conformidad entre el ambiente jerárquico de prestigio de los concejos, cristalizado en los asientos en el escenario del parlamento, y el rango político atribuido por el rey, pero con retraso, es decir, esa alteración no era inmediata $^{18}$.

Para el periodo anterior a 1481 se desconocen figuraciones similares. Sabemos que Coimbra se sentaría a la derecha de Lisboa desde el reinado de D. João I, lo que se confirma en $1436^{19}$. Existe también una noticia de malestar causado por las precedencias de los delegados de las comunidades, a finales de los años sesenta del siglo $\mathrm{XV}^{20}$, y el argumento regio utilizado en respuesta a esta protesta invocaba el cumplimiento de un esquema jerarquizado, que se remontaba a veinte años atrás.

Dejando a un lado, por ausencia de testimonios, la cuestión de los asientos asignados en la ceremonia y centrándonos en la identificación de ciudades y villas que desempeñaron un papel político activo en las cortes, en momentos cruciales, se concluye que casi todas ellas se insertaban en el grupo de las mencionadas en 1481 . Nos estamos refiriendo a los treinta y cuatro con-

${ }^{12}$ Luís Miguel Duarte fue el autor que más dudas planteó sobre esta representación de 1481 . Cf. Duarte 2003, 2005, p. 255.

${ }^{13}$ Ambas (1481 y 1535) confrontadas por Sousa 1990, vol. I, pp. 192 y ss.

${ }^{14}$ Cf. Cardim 1998, pp. 66 y ss.

${ }^{15}$ Cf. Cortes de 1502, pp. 15-16.

16 Villa notable era un rango intermedio entre las villas y las ciudades, atribuido por los monarcas. Véase Ordenações Afonsinas ed. Mário Júlio de Almeida Costa e Eduardo Borges Nunes, Liv. I, Tit. II, Par. IV, p. 19 y Ordenaçoens do Senhor Rey D. Manuel, Liv. I, Tit. II, Par. XXII, p. 41.

${ }^{17}$ Hasta los años sesenta del siglo XV, solo eran ciudades las nueve sedes episcopales portuguesas. En 1464, el rey Afonso V otorgó el título de ciudad a Bragança, y los monarcas del siglo XVI lo mantuvieron. Véase Azevedo, 1917, pp. 10-11.

${ }^{18}$ Además, había una gran movilidad en los asientos, si bien la mayoría de las veces era una movilidad horizontal, es decir, la jerarquía cambiaba en el mismo banco, los que se sentaban al centro y a la derecha de quién. Véase en Costa 2014, pp. 68-69.

${ }^{19}$ Cortes 1436, 1438, p. 38.

${ }^{20}$ Sousa 1990, vol. I, p. 132: Duarte 2003; Costa 2014, p. 65. 
cejos listados en 1385, en el auto de elección de D. João $\mathrm{I}^{21}$, a los que firman el regimento del reino ${ }^{22}$, en 1438, y a los que dan anuencia al acuerdo de 1439 , atribuyendo la regencia, en exclusiva, a D. Pedro ${ }^{23}$.

En las cortes de Torres Novas de 1438, durante la minoría regia de Afonso V (1438-1481), treinta y cinco ciudades y villas estuvieron involucradas en estos trámites, habiendo firmado sus representantes, por delegación, varios documentos ${ }^{24}$. Todas ellas tenían asiento en 1481. Aunque no se pueda garantizar que solamente estos concejos actuaran en el proceso, no parece casualidad que los hubieran sancionado ellos mismos, subscribiendo los diplomas.

En las cortes de Lisboa de 1439 fue ratificada, por setenta y dos concejos, la decisión de designar el infante D. Pedro regente del reino. Una vez contrastado el número de participantes con las ochenta comunidades con asiento en la asamblea de 1481, apenas se manifiestan algunas discrepancias, ya que sólo hay dos villas que no constan en la planta mencionada ${ }^{25}$.

${ }^{21}$ Elección del monarca en el parlamento, a consecuencia de la llamada revolución de $1383 / 1385$. Atendiendo a concejos importantes no presentes, porque en ese momento tomaron partido por Dña. Beatriz, apenas son mencionadas ocho villas no incluidas en la planta de 1481 (Penela, Celorico da Beira, Soure, Marialva, Évoramonte, Lousã y Amieira), cuatro de las cuales jamás volverán. Todas las demás veintiséis ciudades y villas están indicadas en la representación gráfica de 1481, en los bancos que se identifican entre paréntesis: (1) Lisboa, Coimbra, Évora, Porto; (2) Lamego, Silves; (3) Elvas; (4) Tomar; (5) Montemor-o-Velho; (7) Setúbal, Portalegre, Almada e Nisa; (8) Serpa, Mourão; (9) Pinhel, Abrantes, Avis; (10) Alegrete; (11) Penamacor, Castelo de Vide; (12) Fronteira; (14) Monsanto; (16) Monsaraz. No sentados: Santiago do Cacém, Pombal. Vease, Caetano 1985, pp. 92-93; Sousa 1985, p. 19; 1990, vol. II, p. 9.

${ }^{22}$ Regimento del reino fue un texto "constitucional" elaborado pelo infante D. Henrique, uno de los tíos del joven monarca, para establecer las normas de funcionamiento de la regencia.

${ }^{23}$ Tío del joven rey que acababa de ser aclamado y que será regente del reino entre 1439 y 1449. Véase sobre estas dos coyunturas políticas Moreno 1973, pp. 3-65.

${ }^{24}$ Había 17 concejos que firmaron la constitución del regimento y la protesta de la reina; 34 concejos subscribieron la declaración sobre la composición y el funcionamiento del consejo regio; 15 concejos que firmaron la publicación del regimento con la protesta de no ser preservados sus privilegios; 16 concejos firmaron la notificación de la respuesta de la reina, Cortes 1438, pp. 46-47, 52-56. La distribución de las ciudades y villas con participación documentada en 1438, con base en la representación gráfica de 1481, en los bancos identificados ente paréntesis es la siguiente; (1) Lisboa, Coimbra, Évora, Santarém, Porto; (2) Lamego Viseu, Silves, Guarda; (3) Elvas, Guimarães, Tavira, Leiria; (4) Estremoz, Montemor-o-Novo, Tomar, Covilhã; (5) Vila Real, Moura, Faro, Ponte de Lima; (6) Alenquer, Castelo Branco, Torres Novas, Aveiro; (7) Óbidos, Setúbal; (8) Serpa, Trancoso, Olivença; (9) Pinhel, Loulé, Avis; (10) Valença, Monção; (12) Fronteira; (13) Viana do Castelo, Moncorvo; (14) Miranda do Douro.

${ }^{25}$ Se trata de Aveiras y Castro Verde. Además, no subscriben el acuerdo dos villas de la Casa de las Reinas, una de una Orden Militar y todas las villas de la Casa de Braganza, aunque algunas estuvieran presentes en esas cortes. Véase Cortes 1439, pp. 43-48; Sousa 1990, vol. II, pp. 17-20. Es la siguiente la distribución de las ciudades y villas con participación en las cortes de 1439, de acuerdo con la representación gráfica de 1481, en los bancos identificados entre paréntesis: (1) Lisboa, Coimbra, Évora, Santarém, Porto; (2) Braga, Lamego Viseu, Silves, Guarda; (3) Elvas, Guimarães, Beja, Tavira, Leiria; (4) Estremoz, Montemor-o-Novo, Tomar, Covilhã, Bragança; (5) Vila Real, Moura, Faro, Montemor-o-Velho, Ponte de Lima; (6) Castelo 
Por informaciones posteriores a 1481, se concluye que la asignación de posiciones a los procuradores concejiles en las ceremonias protocolarias del parlamento se vincula a la jerarquía formal de las ciudades, villas notables y otras villas. En contrapartida, los datos recogidos a lo largo del siglo XV, anteriores a esa reunión, nos permiten aseverar que los concejos participantes en esta subestructura del sistema político ${ }^{26}$ figuraban en los bocetos que representaban la ceremonia inaugural de las cortes.

Una última cuestión se puede formular en el ámbito del cotejo entre la representación y lo "real de lo representado": ¿Acaso la jerarquía de la ocupación de bancos clasifica distintas competencias políticas de los centros urbanos? En realidad, esta es una pregunta cuasi retórica. Armindo de Sousa presentó indicios de la existencia de reuniones parlamentarias reservadas a las ciudades ${ }^{27}$ y es conocida la exclusiva selección de sedes episcopales de la primera fila (aunque la villa de Santarém también la ocupaba), en las propuestas de inclusión de delegados de los concejos en el consejo regio, en 1385 y $1438^{28}$, o en las cortes restringidas anuales de $1438^{29}$. Así, además del innegable liderazgo parlamentario de Lisboa, es cierto que las ciudades y villas, que en la sesión inaugural de cortes estaban más cerca del rey, controlaban la formulación de los capítulos generales ${ }^{30}$. ¿Pero qué pasaba con las otras, las que participaban en la ceremonia a partir Dos bancos de Trás? ${ }^{31}$. Aquí se abre un filón de investigación todavía por desarrollar.

La segunda serie de reflexiones que el dibujo de 1481 desencadena se relaciona con lo omitido, a saber, las delegaciones que acuden a cortes pero que no tienen un asiento fijo. Armindo de Sousa ha revelado testimonios de la comparecencia de cincuenta en estas condiciones, entre 1385 y $1490^{32}$.

Branco, Torres Novas, Aveiro, Sintra; (7) Óbidos, Setúbal, Torres Vedras*, Alcácer do Sal, Portalegre, Almada*, Nisa; (8) Serpa, Mourão, Lagos, Trancoso, Olivença; (9) Pinhel, Abrantes, Arronches, Loulé, Avis; (10) Valença, Monção, Freixo de espada à Cinta, Alegrete, Alter do Chão; (11) Penamacor, Marvão, Castelo de Vide, Sertã, Castelo Rodrigo; (12) Monforte, Veiros*, Fronteira, Campo Maior, Crato; (13) Viana do Castelo, Palmela, Castro Marim, Cabeço de Vide Moncorvo; (14) Monsanto, Garvão, Coruche, Panoias, Miranda do Douro; (15) Albufeira, Ourique, Portel*; (16) Vila Viçosa*, Penela, Monsaraz*, (*concejos que no subscriben el acuerdo).

${ }^{26}$ Concepto recogido en Sousa 1999, vol. I, pp. 90 y ss.

${ }^{27}$ Sousa 1990, vol. I, p. 148.

${ }^{28}$ Costa 2014, p. 66.

${ }^{29}$ Caetano 1985, pp. 92-93; Cortes 1438, pp. 42; Sousa 1985, p. 15; 1990, vol. I, pp. 111 y ss.

${ }^{30}$ Véase Sousa 1985 , pp. 19 y ss.

${ }^{31}$ Retomamos la expresión del título de la interesante sesión presentada por Luis Miguel Duarte, Diogo Faria y Eugénia Mota en las I ${ }^{a}$ Jornadas Internacionais de Idade Média (celebradas en octubre de 2016 en Castelo de Vide).

32 Véase la completa sistematización de la presencia de estas delegaciones en todas las reuniones de cortes, Sousa 1990, vol. II, pp. 27-68. 
Desde el punto de vista de la corona, la gran diferenciación de reconocimiento formal de competencia política a los concejos era la convocatoria, ya que ésta se dirigía solamente a algunos para presentarse en parlamento. Pero, el problema que se plantea es el siguiente: ¿Las ciudades y villas convocadas coinciden con las que son representadas en el cuadro? ¿Habría otras que eran también llamadas, pero sus delegados no figuraban sentados en la ceremonia inaugural ${ }^{33}$ ? Armindo de Sousa no es concluyente en su respuesta ${ }^{34}$, al asegurar que los datos recogidos en 1502 permiten afirmar que las ciudades y villas citadas a cortes coincidían con las que tenían asiento ${ }^{35}$, pero se trata de una información que no puede generalizarse.

Expongamos el ejemplo de Caminha. Sus delegados estuvieron presentes en cortes en los años $1439,1455,1459$ y en $1481-1482^{36}$, pero solamente en 1498 la villa había sido convocada por primera vez y le fue atribuido un lugar ${ }^{37}$. En un capítulo especial de ese año, Caminha solicitaba al rey un documento que validase el llamamiento y la asignación de un asiento, como ocurría con los demás concejos en las mismas circunstancias ${ }^{38}$.

¿Cabe preguntarse si las delegaciones no llamadas ${ }^{39}$ tenían el derecho a participar en las sesiones de trabajo, en las cuales los representantes de los "pueblos" 40 fundían sus capítulos especiales y tomaban otras decisiones sobre temas propuestos por el rey? Pero esta es todavía una cuestión abierta.

Hasta este momento nos hemos ocupado del enfoque político de la jerarquización urbana medieval portuguesa. A continuación, introduciremos el factor jurisdiccional en el debate, una vez dicho que, entre las ochenta comunidades representadas en la planta de 1481, se mezclaban ciudades, villas de realengo y centros urbanos dependientes de señores nobles o eclesiásticos.

\footnotetext{
${ }^{33}$ Cuestión que se aplica desde luego a los delegados de las siete villas que figuran de pie en la representación gráfica hecha por el secretario del rey en 1481. Véase nota 9. En las plantas posteriores $(1535,1619)$ no se incluyen delegaciones con lugar sentado, Cardim 1998, pp. 6465.

${ }^{34}$ Sousa 1990, vol. I, p. 193. fecha.

${ }^{35} \mathrm{Si}$ son comparados con las representaciones gráficas existentes antes y después de esa

36 Sousa 1990, vol. II, p. 41.

37 "Item Senhor a dicta villa atee ora nunca ffoy chamada quando sse faziam cortes E ora vossa alteza mandou que viessem procuradores della a estas cortes E lhes mandou dar assentos", Cortes 1498, p. 366. p. 17.

${ }^{38}$ Pero, en la lista de 1502 para el llamamiento a cortes, no figuraba esta villa, Cortes 1502,

${ }^{39}$ Armindo de Sousa ha hecho esta cuestión para las delegaciones paralelas que no podrían presentar las firmas de los oficiales concejiles y el sello del concejo. Véase Sousa 1990, vol. I, pp. 210-214, pero las otras delegaciones no llamadas podían cumplir estos requisitos.

${ }^{40}$ Adoptamos la palabra "pueblos" con la significación de tercer estado, tal como era utilizada en la documentación de cortes.
} 


\section{LAS CIUDADES Y VILLAS SEÑORIALES EN CORTES}

En este segundo apartado, la figuración de 1481 será utilizada para visualizar gráficamente el panorama jurisdiccional del mundo urbano portugués, en la Edad Media. Nos proponemos plantear la definición y evolución jurisdiccional de las ciudades y villas que accedían formal y jerárquicamente al reducto escénico de proximidad al rey y asumían la representación de los "pueblos". Centraremos nuestra atención en las competencias políticas de los concejos señoriales.

Con base en la asignación de asientos a los delegados municipales en la ceremonia inaugural de cortes, se ha diseñado un cuadro que indica la situación jurisdiccional de esos concejos, en el año 1410. La elección de la fecha no es arbitraria, una vez que coincide con un intervalo de tiempo, en el que hay un mayor número de ciudades y villas realengas. De hecho, las dos sedes episcopales de señorío eclesiástico -Braga y Porto ${ }^{41}$ - acababan de ser incorporadas en la corona y aún no se había iniciado la constitución de la Casa de los Infantes, con la respectiva atribución de dominios.

Cuadro 2. Situación jurisdiccional de los concejos en 1410

(con recurso al probable asiento de sus delegados en cortes)

\begin{tabular}{|c|c|}
\hline 1 & Lisboa, Coimbra, Évora, Santarém, Porto \\
\hline 2 & Braga, Lamego, Viseu, Silves, Guarda \\
\hline 3 & Elvas, Guimarães, Beja, Tavira, Leiria \\
\hline 4 & Estremoz, Montemor-o-Novo, Tomar, Covilhã, Bragança \\
\hline 5 & Vila Real, Moura, Faro, Montemor-o-Velho, Ponte de Lima \\
\hline 6 & Alenquer, Castelo Branco, Torres Novas, Aveiro, Sintra \\
\hline 7 & $\begin{array}{l}\text { Óbidos, Setúbal, Torres Vedras, Alcácer do Sal, Portalegre, Almada } \\
\text { y Nisa }\end{array}$ \\
\hline 8 & Serpa, Mourão, Lagos, Trancoso, Olivença \\
\hline 9 & Pinhel, Abrantes, Arronches, Loulé, Avis \\
\hline 10 & Valença, Monção, Freixo de espada à Cinta, Alegrete, Alter do Chão \\
\hline 11 & Penamacor, Marvão, Castelo de Vide, Sertã, Castelo Rodrigo \\
\hline 12 & Monforte, Veiros, Fronteira, Campo Maior, $\underline{\text { Crato }}$ \\
\hline 13 & $\begin{array}{l}\text { Viana do Castelo, Palmela, Castro Marim, Cabeço de Vide, } \\
\text { Moncorvo }\end{array}$ \\
\hline
\end{tabular}

${ }^{41}$ Sobre el pasaje del señorío de las dos ciudades episcopales a la corona, véase: Marques 1997; Marques 1994, pp. 238-243; Sousa 1990, pp. 589-616; Duarte 1985, pp. 3-16; Costa, 2006, pp. 75-85. 


\begin{tabular}{|c|l|}
\hline 14 & Monsanto, Garvão, Coruche, Panoias, Miranda do Douro \\
\hline 15 & Albufeira, Borba, Ourique, Portel, Arraiolos \\
\hline 16 & Vila Viçosa, Penela, Monsaraz \\
\hline
\end{tabular}

Leyenda: texto sin diacrisis: centros urbanos de la corona; subrayado: centros urbanos de las órdenes militares; cursiva: centros urbanos de la Casa de las Reinas; negrita: centros urbanos de la nobleza

Con excepción de los representantes de Tomar, villa de señorío de la Orden del Temple, y después de Cristo, desde el siglo XII ${ }^{42}$, los cinco primeros bancos, o sea, la cumbre de la jerarquía, eran ocupados por delegados de ciudades y villas de realengo. Así, en el cómputo general, la corona dominaba cincuenta y tres de los ochenta concejos con presunta representación parlamentaria ${ }^{43}$; las órdenes militares, quince ${ }^{44}$; la Casa de las Reinas, cinco $^{45}$; y la nobleza, siete ${ }^{46}$. Era muy distinto el panorama jurisdiccional, en 1481, como en seguida veremos.

Cuadro 3. Situación jurisdiccional de los concejos en 1481

(con recurso al probable asiento de sus delegados en cortes)

\begin{tabular}{|c|l|}
\hline 1 & Lisboa, Coimbra, Évora, Santarém, Porto \\
\hline 2 & $\underline{\text { Braga }, \text { Lamego, Viseu, Silves, Guarda }}$ \\
\hline 3 & Elvas, Guimarães, Beja, Tavira, Leiria \\
\hline 4 & Estremoz, Montemor-o-Novo, Tomar, Covilhã, Bragança \\
\hline 5 & Vila Real, Moura, Faro, Montemor-o-Velho, Ponte de Lima \\
\hline 6 & Alenquer, Castelo Branco, Torres Novas, Aveiro, Sintra \\
\hline 7 & $\begin{array}{l}\text { Óbidos, Setúbal, Torres Vedras, Alcácer do Sal, Portalegre, Almada } \\
\text { y Nisa }\end{array}$ \\
\hline 8 & Serpa, Mourão, Lagos, Trancoso, Olivença \\
\hline 9 & Pinhel, Abrantes, Arronches, Loulé, Avis \\
\hline 10 & $\begin{array}{l}\text { Valença, Monção, Freixo de espada à Cinta, Alegrete, Alter do } \\
\text { Chão }\end{array}$ \\
\hline
\end{tabular}

\footnotetext{
${ }^{42}$ Véase Conde 1996.

${ }^{43} \mathrm{Cf}$. lo que escribimos a propósito de la convergencia entre la ocupación de los asientos en 1481 y las comunidades actuantes en cortes en periodos anteriores.

${ }^{44}$ Véanse las monografías sobre villas y la bibliografía sobre las Órdenes Militares y la jurisdicción que mantenían en Oliveira 2009, 2013; Pereira 2000.

${ }^{45}$ Véanse las monografías sobre villas de las Casas de las Reinas en Carvalho 1992; Ferro 1996; Rodrigues 1995; Silva 1997; Vieira 2011. Además, véanse los estudios sobre la Casa de las Reinas sistematizados en las biografías publicadas hace poco tiempo en Rodrigues, Sá, Silva 2011-2013.

${ }^{46}$ Seis pertencían a Nuno Alvares Pereira, véase Cunha 1990, pp. 93-97; Silva 1991.
} 


\begin{tabular}{|c|c|}
\hline 11 & Penamacor, Marvão, Castelo de Vide, Sertã, Castelo Rodrigo \\
\hline 12 & Monforte, Veiros, Fronteira, Campo Maior, Crato \\
\hline 13 & Viana, Palmela, Castro Marim, Cabeço de Vide, Moncorvo \\
\hline 14 & Monsanto, Garvão, Coruche, Panoias, Miranda do Douro \\
\hline 15 & Albufeira, Borba, Ourique, Portel, Arraiolos \\
\hline 16 & Vila Viçosa, Penela, Monsaraz \\
\hline
\end{tabular}

Leyenda: texto sin diacrisis: centros urbanos de la corona; subrayado: centros urbanos de las órdenes militares; cursiva: centros urbanos de la Casa de las Reinas; negrita: centros urbanos de la nobleza; cursiva y negrita: centros urbanos eclesiásticos

El cuadro muestra que en los cinco primeros bancos se acomodaban los representantes de catorce núcleos urbanos de la corona ${ }^{47}$, de una ciudad de señorío eclesiástico - una vez que Braga regresara a sus arzobispos ${ }^{48}$-, y los delegados de Tomar, además los de ocho centros urbanos pertenecientes a la nobleza ${ }^{49}$. El paisaje jurisdiccional reflejado por los once bancos restantes prueba que el señorío de los concejos de la Casa de las Reinas y de las Órdenes Militares se mantiene inmutable, indicando que estas villas conocieron una historia señorial lineal. Así mismo, existe un gran incremento de los núcleos urbanos dominados por los hidalgos, sumando a los ocho anteriores dieciocho villas más ${ }^{50}$.

Estas dos "representaciones", aunque nos transmitan el crecimiento del poder señorial y su reflejo en concejos, con participación reconocida y valorada en el sistema político, necesitan ser matizadas. Ya que esta afirmación no se refiere al cruce verificado en la Baja Edad Media entre el poder señorial de la alta nobleza titulada, sobre todo elementos de la familia real y las administraciones de las Órdenes Militares, originando convergencia jurisdiccional ${ }^{51}$. Ni tampoco la afirmación remite al entramado de derechos que antecedían, acompañaban o se sumaban a las donaciones de mero y mixto imperio, condicionando o potenciando la capacidad de ejercicio de dominio de cada señor sobre sus centros urbanos ${ }^{52}$.

\footnotetext{
${ }^{47}$ Recordemos que Coimbra había sido, entre 1416 y 1449, sede del ducado del mismo nombre, pero entretanto regresara a la corona, Moreno 1983-1984, 1997; Coelho 1993 1995.

${ }^{48}$ Braga había pertenecido a la corona desde 1402 hasta 1472. Véase Sousa 1990a.

${ }^{49}$ Sobre estas Casas Señoriales y las villas que señoreaban, véase Cunha 1990; 1996; Campos 2004; Domingues 2008; Ferreira 2010; Oliveira 1999, 2000-2001; Moreno 1983-1984, 1984, 1987, 1989; Silva 1991; Sousa 2006; Vicente 2012.

${ }^{50}$ Véase Moreno 1984, 1984a, 1989; Vieira 2011; Vilar 1988.

${ }^{51}$ Véase Vasconcelos 2008.

${ }^{52}$ Véase Cunha 1996, 2005.
} 
El enfoque escogido es otro, ya que la cuestión sobre la cual pretendemos reflexionar sería saber ¿hasta qué punto la señorialización de los centros urbanos, acentuada a lo largo del siglo XV, se erigió en efectiva barrera a la comunicación política entre los concejos y la corona? El cambio de situación jurisdiccional de veinte y dos concejos con asiento en cortes, entre las fechas de 1410 y 1481, nos lleva a preguntarnos sobre modificaciones de sus competencias políticas.

Empezamos por evocar casos conocidos de comunidades urbanas que, según variados criterios, se considerarían de importancia similar a otras presentes en cortes, y no lograrían alcanzar ese estatuto.

Todos los autores señalan que Barcelos ${ }^{53}$ y Chaves $^{54}$ estuvieron representadas en el parlamento por su señor. De ser así, la interferencia del criterio jurisdiccional en la hipótesis de diálogo entre estas comunidades y el rey habría sido determinante y originaría una fractura. Los primeros testimonios de la presencia de Barcelos en cortes ${ }^{55}$ coinciden con el periodo en que el señorío de Braganza fue desarticulado (1483/1495), más precisamente en $1490^{56}$. Es inequívoca la conexión directa entre el dominio noble y la ausencia de la villa en el parlamento. En lo que a Chaves se refiere, las evidencias no son tan claras. Además de su asistencia a cortes en el reinado de D. Fernando (1367-1383) -cuando era realenga-, lo estuvo también en 1391 y en $1401^{57}$, siendo ya de señorío. Después de una prolongada ausencia (efectiva o de testimonios), la villa habría presentado capítulos especiales en la reunión parlamentaria de $1498^{58}$, una fecha en que, de nuevo, pertenecía a la Casa de Bragança.

Una situación distinta habría experimentado Braga, según los medievalistas portugueses: la ciudad había participado en cortes antes de su integración en la corona, en 1402, pero solo después de esa fecha adquirió asiento propio en el espacio de las solemnidades previas al desarrollo de las sesiones de trabajo ${ }^{59}$. La verdad es que no existe forma de confirmar esta interpretación generalizada - de que Braga no tuviera lugar de asiento antes su salida del se-

\footnotetext{
${ }^{53}$ Barcelos fue donada, en el siglo XIII, al conde del mismo nombre. Después de Aljubarrota, João I entrega la villa a Nuno Álvares Pereira; a su vez, en 1401, este transmite el señorío a su hija y al infante D. Afonso, hijo bastardo de D. João I. Sobre Barcelos, véase Ferreira 1991-1992.

${ }^{54}$ También después de Aljubarrota, la villa de Chaves -hasta entonces realenga- fue concedida a Nuno Álvares Pereira. Sobre Chaves, véase Dias 1990.

${ }_{55}$ Aunque en las cortes de 1472 fuera representada por la ciudad de Porto, Sousa 1990, vol. I, p. 193.

${ }^{56}$ Sousa 1990, vol. II, p. 40.

${ }^{57}$ Marques, Gonçalves, Andrade 1990, p. 29.

${ }^{58}$ Cortes 1498, pp. 374-375.

${ }^{59}$ Braga estuvo presente en las cortes de 1383, Sousa 1990, vol. 1, p. 194.
} 
ñorío-. Además, siendo el lugar donde se realizaron las cortes en 1387, resulta algo raro que el concejo no hubiera asistido a la sesión inaugural, tratándose de una de las nueve ciudades portuguesas, por ser sede de diócesis episcopal.

Sin embargo, se verifica en los tres casos mencionados que, cuando existe una reincorporación al señorío noble o eclesiástico, los concejos permanecían en el parlamento. De hecho, Barcelos, después de un interregno (o ausencia de pruebas), en 1498 y 1502, reaparece en 1535 y con derecho a un asiento en la ceremonia inaugural ${ }^{60}$; además, como ya hemos visto, Chaves estuvo presente en 1498 y Braga se mantuvo desde $1472^{61}$.

Ciertamente, cabe hacer algunas reflexiones sobre el tópico de la representación de una comunidad territorial por su señor en cortes. Parece casi incuestionable que el señor funcionaba como un obstáculo a la capacidad del concejo para participar políticamente en la asamblea que reunía los varios cuerpos del reino. Pero esta explicación puede que no sea unívoca. En concejos que solo lograban alcanzar lo que llamamos el primer grado de competencia política, el titular de la jurisdicción podría ser el vehículo que facultaba la llegada de las protestas de la villa al parlamento. Habría sido el caso de Gonçalo Botelho, señor de Albergaria, que, en 1439, fue comisionado por el concejo como procurador, encargado de presentar capítulos especiales contra el hospedaje abusivo de hidalgos en la localidad ${ }^{62}$, manifestando la comunión de intereses con la comunidad.

En cuanto a los concejos que recibían cartas regias de convocatorias para acudir al parlamento, por testimonios más tardíos, se conoce el proceso por el cual la comunidad elegía al señor como su delegado, cumpliendo todas las formalidades legales. Es el caso de la ciudad de Bragança, en 1502, que alegaba cuestiones financieras y logísticas para escoger al duque ${ }^{63}$.

Es probable que la presunta representación de los concejos por su señor en cortes no fuese más que un escenario residual. Recordemos que este planteamiento solo se focaliza en el ámbito del acceso de los concejos señoriales a cortes y no en las innumerables vicisitudes prácticas que pueden obstruir el diálogo político que esas comunidades mantenían con la corona. Naturalmente, en ese enfoque más amplio juegan distintas circunstancias de las cuales señalamos: (I) el carácter definitivo -o, por lo menos, continuado- con el que los núcleos urbanos permanecen en posesión de los mismos señores, por oposición a la extemporaneidad del dominio; (II) el tipo de derechos efectiva-

\footnotetext{
${ }^{60}$ Ferreira 1991-1992, p. 7; Sousa 1990, vol. I, p.191-193

${ }^{61}$ Véase Sousa 1990a.

${ }^{62}$ Cortes 1439, pp. 144-146.

${ }^{63}$ Cortes 1502 , pp. 39-40. En esta asamblea se verifican varios mecanismos de representación de concejos, incluso aconsejados por el rey.
} 
mente otorgados al donatario; (III) el interés del señor por su tierra, manifestado en una intervención más rigurosa o más blanda; (IV) la proximidad física de sus dominios; (V) la vigilancia sobre los oficiales periféricos que controlaban los organismos locales; (VI) el estatuto político que la personalidad/institución que ostentaba la ciudad o villa beneficiaba en el reino ${ }^{64}$.

A todas las anteriores condiciones se suma la más determinante, a saber, los lazos de dependencia eficaces que el señor logra establecer con la oligarquía municipal de la ciudad o villa. Un requisito que entronca directamente con nuestro tema, dado que los delegados a las reuniones de cortes constituían el espejo de la elite del poder concejil, que veremos a continuación.

No vamos a intentar proponer interpretaciones sobre la influencia que los señores jurisdiccionales tuvieron en el gobierno municipal de sus ciudades y villas, porque los estudios monográficos en para cronología amplias no se encuentran aún elaborados, o no se pueden producir por ausencia de datos $^{65}$. Además, las distintas coyunturas rompen los equilibrios de la fidelidad de los oligarcas, y la permanencia de los mismos hombres y familias, al frente de los destinos de un concejo, no implica una inmutabilidad de sus lealtades y acostamientos. Por lo que no existen teorías explicativas, sino solo distintos ejemplos contradictorios. No obstante sabemos que el cambio jurisdiccional de los concejos tuvo impacto en la composición del personal político de las ciudades y villas y, en consecuencia, en los delegados a cortes. Por no mencionar el caso mejor estudiado en Portugal -el de los oficiales territoriales del infante D. Pedro, perseguidos tras la batalla de Alfarrobeira, en $1449^{66}$-, presentemos el excelente ejemplo de Montemor-o-Novo, en 1483, cuando el cambio súbita de jurisdicción implicó una alteración en la oligarquía del lugar ${ }^{67}$.

Avancemos con una cuestión: ¿hasta qué punto hubo control por parte del señor de las peticiones presentadas en cortes por ciudades y villas de su jurisdicción ${ }^{68}$ ? No ha sido desarrollado un análisis profundo, pero, en los datos de 1439 se encuentran críticas de concejos señoriales contra sus señores ${ }^{69}$,

\footnotetext{
${ }^{64}$ Seguimos aquí las variables enunciadas por Costa 1999, pp. 246-253.

${ }^{65}$ Las monografías de ciudades y villas (hablamos de las que tienen asiento en cortes y que en cualquier época fueron de señorío) no siempre plantean los temas de los cuadros humanos del gobierno municipal, sea por opción, sea por imposibilidad de las fuentes.

${ }^{66}$ Moreno 1973.

${ }^{67}$ Se repite que se estudia apenas el impacto político de la transferencia de jurisdicción y no el fuerte impacto fiscal, por ejemplo, que ese pasaje de señorío implica. Véase Fonseca 1998; Domingues 2008.

${ }^{68} \mathrm{Si}$ la cuestión es relevante la respuesta es una mera hipótesis de trabajo. Sería necesario elaborar un estudio profundo sobre el tema de las quejas contra los señores hechas durante un largo período de tiempo.

${ }^{69}$ Los ejemplos siguientes son retirados de las cortes de 1439. Naturalmente, en la coyuntura de esas cortes -que entregan la regencia en exclusiva al infante D. Pedro- las tierras de la reina
} 
mientras otros se dirigen al rey como si no hubiera otro poder intermedio ${ }^{70}$. Incluso es el propio monarca quien, en su respuesta, recuerda a una villa la necesidad de consultar al señor en algunos asuntos ${ }^{71}$. Se verifica, también, una actitud suplicante de los "pueblos", dirigida sea al rey sea al señor, sin que haya una constancia de una presunta delimitación de competencias de mando ${ }^{72}$.

Cabe finalmente preguntarse, en lo que a la presión ejercida por los señores se refiere, hasta qué punto son distintas las peticiones de las comunidades realengas y de señorío. Un análisis comparativo de las protestas, realizado sistemáticamente solo para las cortes de $1439^{73}$, no permite identificar una gran diferencia entre las presentadas por ciudades y villas de la corona y de señores. Así, las críticas dirigidas a nobles que poseían jurisdicción de mero y mixto imperio de villas, y a otros hidalgos que tenían propiedades, rentas y derechos en un centro urbano realengo y/o jurisdicciones en el término, son similares. De hecho, en el siglo $\mathrm{XV}$, siguiendo el proceso que se va a intensificar en la segunda mitad del siglo, muchas localidades, aunque permaneciesen en el dominio de la corona, sufrían la acción opresiva de los nobles ${ }^{74}, \mathrm{o}$ el establecimiento de fuertes lazos entre hidalgos y sus oligarquías concejiles. Por esta razón, era notorio el deseo de controlar las elecciones municipales de los concejos urbanos realengos, por parte de los nobles que ejercían dominio

Dña. Leonor, caída en desgracia, juegan con la cuestión política e intentan obtener dividendos. Tal ha ocurrido con Óbidos, Sintra, Torres Novas y Torres Vedras en 1439. Cortes 1439, pp. 350-355; 420-429; 442-448; 449-451. Pero, en la misma asamblea, villas de las órdenes y de los infantes también criticaron a sus señores: Avis, Cortes 1439, pp. 179-180, Covilhã, Cortes 1439, pp. 234-235; Veiros, Cortes 1439, p. 468.

${ }^{70}$ Es el caso de los capítulos de Aveiro, Cortes 1439, pp. 176-178 y de Coimbra, Cortes 1439 , pp. 232-233. En realidad, pero no formalmente, Aveiro y Coimbra perteneciendo al infante D. Pedro, regente, no tenían otro poder intermedio.

${ }^{71}$ En 1439 el rey ordena a la villa de Alcácer que envíe requerir al Maestre de Santiago un asunto sobre que le ha hecho petición, Cortes 1439, pp. 147-148.

72 Cortes 1439, p. 478 (Viseu).

${ }^{73}$ Somos conscientes del insuficiente análisis de datos elaborado para este apartado (asamblea de 1439) y de la obligatoriedad de proceder a encuestas más amplias para comparar las peticiones presentadas en cortes, por las ciudades y villas señoriales, a lo largo del tiempo. Véase, por ejemplo: Andrade; Gomes (1983-1984).

${ }^{74}$ Por ejemplo, continuando con irregularidades señaladas por los concejos en las cortes de 1439, sabemos que el conde de Arraiolos tenía derechos en Beja aunque la villa era de la corona, Cortes 1439, p. 186. La villa regia de Bragança pide juiz de fora (oficial periférico que tiene funciones semejantes al corregidor castellano) -lo que no es muy normal- debido a la interferencia de un miembro de la Familia Real que no permitía la ejecución de la justicia, Cortes 1439 , p. 204. Al revés, en los capítulos de Valença se dice que ha sido solicitado por algunos que son allegados a hidalgos la nominación de juiz de fora y no por el concejo (p. 462). También Pedro Lourenço de Ferreira tenía derechos en Penamacor que le habían sido concedidos por el rey, solicitando al concejo que los quitase, Cortes 1439, pp. 359-360. A su vez, Ponte de Lima reclama porque Leonel de Lima poseía una casa en la villa, lo que iba contra los privilegios, Cortes 1439, pp. 371-372. Véase sobre este tema Moreno 1984, 1984a, 1987, 1989. 
sobre tierras cercanas a los mismos ${ }^{75}$. Y que el cuerpo oligárquico ejercía una fuerte atracción sobre los señores se concluye, por antinomia, a partir de las múltiples peticiones en el sentido de apartarlos de las reuniones concejiles ${ }^{76}$.

De este recorrido sobre los eventuales cambios de las competencias políticas de las ciudades y villas que, a lo largo del siglo $\mathrm{XV}$, fueron incorporadas a señoríos, quedan cuestiones por conocer, aunque nada indica, de acuerdo con las fuentes compulsadas, que hubiesen perdido formalmente la línea de comunicación con la corona.

\section{CONCLUSIÓN}

En el título de este texto planteamos analizar los factores político y jurisdiccional como criterios de jerarquización de las ciudades y villas portuguesas en la baja Edad Media.

Es conocido que la competencia de comunicación política básica de los concejos -comunidades territoriales con alguna autonomía reconocida de autogobierno- se traducía en la capacidad de exponer al monarca cualquier asunto de la colectividad. Pero la llegada a una ciudad o villa de la carta convocatoria para presentarse en cortes, y unir sus voces a otras en una asamblea representativa del reino, era el más alto rango de participación política a que podían aspirar, introduciendo una innegable distinción entre concejos.

En el primer apartado del artículo, retomamos un conocido bosquejo que enumera las ochenta ciudades y villas portuguesas, por orden de importancia, llamadas a participar en el sistema político en el ámbito del parlamento. Creemos haber añadido algunos argumentos más -a los apuntados por reputados medievalistas- acerca de que la ordenación de delegados en los dieciséis bancos no era simbólica, reductora e inmutable; por el contrario, existía movilidad de acuerdo con los cambios de estatus de los centros urbanos. Además, esa clasificación política no se mantenía aislada de otros criterios de jerarquización de ciudades y villas, en términos demográficos o económicos. Claro está que, en el interior de este grupo, surgieron las conocidas rivalidades políticas entre las ciudades y villas notables del reino -y sobre todo de Lisboa, la caput regni-, mientras es ahora cuando empieza a estudiarse el estatus de los concejos cuyos delegados a cortes se sentaban en "los bancos traseros".

En el segundo apartado, elegimos reflexionar sobre la evolución jurisdiccional de las ciudades y villas con representación en cortes. El bosquejo

\footnotetext{
${ }^{75}$ Véase en relación con el término de Pinhel, Cortes 1439, pp. 362-364.

${ }^{76}$ Véase Moreno 1984.
} 
de 1481 pasó a ser un mero escenario de observación del cambio de señor de veinte y dos concejos, a lo largo del siglo XV, y las fuentes fueron estudiadas a partir del mantenimiento o cambio de las prerrogativas políticas de esas comunidades. La afirmación, muchas veces repetida, de que los señores jurisdiccionales representaban en cortes sus ciudades y villas tiene que matizarse, ya que al menos hubo variaciones en el tiempo. Los casos conocidos que garantizan esa aserción son esclarecedores, pero no constantes y, una vez convocados al parlamento, esos concejos, estando o no bajo el dominio señorial, intentaban mantenerse en cortes y lo lograban.

Las ciudades y villas que pasaban a los señores no perdían su capacidad política primaria -la de comunicarse con el monarca-y, por lo menos en términos formales, la presencia en cortes de sus delegados se mantenía, es decir, seguían recibiendo las cartas de convocatoria para presentarse al parlamento. Aunque limitados al análisis de las protestas disponibles para la asamblea de 1439 , no se concluye que el criterio jurisdiccional fuese determinante para uniformizar un tipo de discurso "domesticado" de los concejos señoriales. Esto naturalmente no implicaba que la dominación de los señores no se ejerciese. Pero, para el monarca, las ciudades y villas seguían representando el conjunto de los "pueblos" y hablaban en nombre de todos, fuesen o no señoriales.

\section{FUENTES Y BIBLIOGRAFÍA CITADA}

\section{FUENTES PUBLICADAS}

Azevedo, Pedro de (1917), As cartas de criação de cidade concedidas a povoações portuguesas, "Boletim da Segunda Classe da Academia das Ciências" 10, pp. 930-971.

Chaves, Álvaro de, Livro de Apontamentos 1438-1489. Códice 443 da Colecção Pombalina da BNL, ed. Anastásia Mestrinho Salgado, Abílio José Salgado, Lisboa, Imprensa Nacional - Casa da Moeda, 1983.

Cortes Portuguesas: Reinado de D. Duarte (Cortes de 1436 e 1438), João José Alves Dias (organização e revisão geral); Pedro Pinto e João José Alves Dias (transcrições); A. H. de Oliveira Marques (revisão); Maria Alexandra Lousada e Manuel Sílvio Alves Conde (colaboração na pesquisa), Lisboa, Centro de Estudos Históricos da Universidade Nova de Lisboa, 2004.

Cortes Portuguesas: Reinado de D. Afonso V (1438), João José Alves Dias e Pedro Pinto (edição); Carlos Silva Moura e Pedro Pinto (transcrições); João José Alves Dias e Pedro Pinto (revisão), Lisboa, Centro de Estudos Históricos da Universidade Nova de Lisboa, 2004. 
Cortes Portuguesas: Reinado de D. Afonso V (Cortes de 1439), Carlos Manuel da Silva Moura e Pedro Miguel Araújo Correia Pinto (edição), Lisboa, Centro de Estudos Históricos da Universidade Nova de Lisboa, 2016.

Cortes Portuguesas: Reinado de D. Manuel I (Cortes de 1498), João José Alves Dias (organização e revisão geral); João José Alves Dias, A. H. de Oliveira Marques, João Cordeiro Pereira e Fernando Portugal (preparação); João José Alves Dias, Pedro Pinto, Maria João Pereira(transcrições); A. H. de Oliveira Marques e Pedro Pinto (revisão), Lisboa, Centro de Estudos Históricos da Universidade Nova de Lisboa, 2002.

Cortes Portuguesas: Reinado de D. Manuel I (Cortes de 1502), João José Alves Dias (organização e revisão geral); A. H. de Oliveira Marques, João Cordeiro Pereira, Fernando Portugal e Saul António Gomes (preparação); Saul António Gomes e João José Alves Dias (transcrições); Pedro Pinto e A. H. de Oliveira Marques (revisão), Lisboa, Centro de Estudos Históricos da Universidade Nova de Lisboa, 2001. Ordenações Afonsinas, ed. Mário Júlio de Almeida Costa e Eduardo Borges Nunes, 5 vols., Lisboa, Fundação Calouste Gulbenkian, 1984.

Ordenaçoens do Senhor Rey D. Manuel (1797-1806), Coimbra, Real Imprensa da Universidade, 5 vols.

BIBLIOGRAFÍA CITADA

Andrade, Amélia Aguiar; Costa, Adelaide Millán (2011), Medieval Portuguese Towns: the Difficult Affirmation of a Historiographical Topic, en Mattoso, José; Rosa, $\mathrm{M}^{\mathrm{a}}$ Lurdes; Sousa, Bernardo Vasconcelos; Branco, $\mathrm{M}^{\mathrm{a}}$ João (eds.), The Historiography of Medieval Portugal c.1950-2010, Lisboa, Instituto de Estudos Medievais, pp. 283-301.

Andrade, Amélia Aguiar; Gomes, Rita Costa (1983-1984), As Cortes de 148182: uma abordagem preliminar, "Estudos Medievais" 3/4, pp. 157211 .

Boissellier, Stéphane (2009), Les documents sériels témoins de l'évolution du peuplement méridional portugais (XIIe-XVIe siècle): apports et limites d'une quantification sommaire et indirecte, en Denjean Claude (ed.), Sources sérielles et prix au Moyen Âge. Travaux offerts à Maurice Berthe, Toulouse, CNRS - Université de Toulouse - Le Mirail, pp. 15-41.

Caetano, Marcelo (1985), A crise nacional de 1383-1385. Subsídios para o seu estudo, Lisboa, Verbo. 
Campos, Nuno Silva (2004), D. Pedro de Meneses e a construção da Casa de Vila Real (1415-1437), Lisboa, Edições Colibri - CIDHEUS.

Cardim, Pedro (1998), Cortes e cultura política no Portugal do Antigo Regime, Lisboa, Edições Cosmos.

Carvalho, Sérgio Luís (1992), Sintra na Idade Média, Sintra, Sintra editora.

Carrasco Manchado, Ana Isabel (2016), ¿Cultura política o cultura de la política en los discursos de la nobleza? Una categoría de análisis para el estudio de la politización de la nobleza castellana en el siglo $X V$, "Studia Historica. Historia Medieval” 34, pp. 27-57.

Coelho, Maria Helena da Cruz (1993), O infante D. Pedro, duque de Coimbra, "Biblos" 69, pp. 15-57.

Coelho, Maria Helena da Cruz (1995), O Concelho e Senhorio de Viseu em Cortes, Actas do Congresso Infante D. Henrique, Viseu e os Descobrimentos (Viseu, 27-29 de Maio de 1993), Viseu, Câmara Municipal de Viseu, pp. 83-112.

Coelho, Maria Helena da Cruz (2011), Municipal Power en Mattoso, José; Rosa, $\mathrm{M}^{\mathrm{a}}$ Lurdes; Sousa, Bernardo Vasconcelos; Branco, $\mathrm{M}^{\mathrm{a}}$ João (eds.), The Historiography of Medieval Portugal c. 1950-2010, Lisboa, Instituto de Estudos Medievais, pp. 209-230.

Conde, Manuel Sílvio Alves (1996), Tomar Medieval. O espaço e os homens, Cascais, Ed. Patrimonia.

Costa, Adelaide Millán (2006), Comunidades urbanas de senhorio eclesiástico: a divergente experiência das cidades do Porto e de Braga, en Estudos em homenagem ao Professor Doutor José Marques, Oporto, Facultade de Letras da Universidade, pp. 77-85.

Costa, Adelaide Millán (2013), A cultura política em ação. Diálogos institucionais entre a Coroa e os centros urbanos em Portugal no século $X I V$, "En la España Medieval” 36, pp. 9-29.

Costa, Adelaide Millán (2014), O impacto urbano no discurso jurídico da baixa Idade Média em Portugal. Uma abordagem possivel, "Edad Media. Revista de Historia” 15, pp. 59-78.

Costa, Adelaide Millán (1999), Projeção Espacial de domínios. Das relações de poder ao burgo portuense (1385-1502), Lisboa, Universidade Aberta (tesis doctoral inédita).

Cunha, Mafalda Soares da (1990), Linhagem, Parentesco e Poder: A casa de Bragança (1384-1483, Lisboa, Fundação da Casa de Bragança.

Cunha, Mafalda Soares da (1996), Práticas do poder senhorial à escala local e regional (fins do séc. XV a 1640), História dos municípios e do poder local em Portugal dos finais da Idade Média à União Europeia, César de Oliveira (dir.), Lisboa, Círculo de Leitores, pp. 143-153. 
Cunha, Mafalda Soares da (2005), Relações de poder, patrocínio e conflitualidade Senhorios e municípios (século XVI-1640), en Cunha, Mafalda Soares da; Fonseca, Teresa (eds.), Os Municípios no Portugal Moderno Dos Forais Manuelinos às Reformas Liberais, Lisboa, Edições Colibri - CIDHEUS-EU, pp. 87-108.

Dias, Nuno José Pizarro Pinto (1990), Chaves Medieval. "Aqua Flaviae" 3 , pp. 35-94.

Domingues, Maria João Monteiro (2008), Uma elite concelhia no Alentejo Quatrocentista: a administração municipal de Montemor-o-Novo, Oporto, Universidade de Porto (tesis de Máster).

Duarte, Luís Miguel (1985), Um burgo medieval que muda de senhor. Episódios da vida do Porto medievo, "Ler História" 5, pp. 3-16. URL:http:// ler.letras.up.pt/uploads/ficheiros/4799.pdf. [consulta:02/09/2017].

Duarte, Luís Miguel (2003), The Portuguese Parliament: are we asking the rigth questions?, "e-JPH" 1/2 [URL: http://www.brown.edu/Departments/Portuguese_Brazilian_Studies/ejph/html/Winter03.htm [consulta:10/09/2017].

Duarte, Luis Miguel (2005), Um país sem cidades?, O mundo urbano em Portugal na Idade Média, en Jimenez, Manuel Gonzalez (ed.), El mundo urbano en la Castilla del siglo XIII, vol. I, Sevilla, Fundación el Monte, pp. 243-257.

Ferreira, Maria da Conceição Falcão (2010), Guimarães: duas vilas, um só povo: estudo de história urbana: 1250-1389, Braga, CITCEM.

Ferro, João Pedro (1996), Alenquer Medieval (Séculos XII-XIV). Subsídios para o seu Estudo. Cascais, Ed. Patrimonia.

Fonseca, J. (1998), Montemor o Novo no Século XV, Montemor-o-Novo, Câmara Municipal de Montemor-o-Novo.

Marques, A. H. de Oliveira (1988 a), Introdução à história da cidade medieval portuguesa, en Novos ensaios de história medieval portuguesa, Lisboa, Presença, pp 13-42.

Marques, A. H. de Oliveira (1988 b), Cidades medievais portuguesas (Introdução metodológica ao seu estudo), en Novos ensaios de história medieval portuguesa, Lisboa, Presença, pp. 43-67.

Marques, A. H. de Oliveira; Gonçalves, Iria; Andrade, Amélia Aguiar (1990), Atlas das cidades medievais portuguesas. Séculos XIV-XV, Lisboa, CEHUNL - INIC.

Marques José (1994), Braga na Crise de 1383-1385, en Relações entre Portugal e Castela nos finais da Idade Média, Lisboa, Fundação Calouste Gulbenkian/Junta Nacional de Investigação Científica, 1994, pp. 238-243. 
Marques José (1997), O Senhorio de Braga, no século XV: principais documentos para o seu estudo, "Bracara Augusta" 46, pp. 3-143.

Moreno, Humberto Baquero (1973), A Batalha de Alfarrobeira. Antecedentes e significado histórico, Coimbra, Biblioteca Geral da Universidade.

Moreno, Humberto Baquero (1983-1984), O infante D. Pedro e o ducado de Coimbra, "Revista de História" 5, pp. 27-51.

Moreno, Humberto Baquero (1984), Abusos e violências na região da Beira Interior durante o reinado de $D$. Afonso $V$, "Revista de História das Ideias" 5, pp. 175-192

Moreno, Humberto Baquero (1984a), A representação do concelho de Guimarães nas cortes de Lisboa de 1446, "Revista da Faculdade de Letras. História" 1, pp. 7-18.

Moreno, Humberto Baquero (1987), Bandos nobiliárquicos em Olivença nos fins do século $X V$, en Primeras Jornadas Ibéricas de Investigadores de Ciencias Humanas y Sociales (Olivenza, 18-19-20 octubre, 1985), Badajoz, Diputación, pp. 637-656.

Moreno, Humberto Baquero (1989), A nobreza do Algarve nos fins da Idade Média. "Revista da Universidade de Coimbra" 35, pp. 367-378.

Moreno, Humberto Baquero (1997), O Infante D. Pedro, Duque de Coimbra. Itinerários e Ensaios Históricos, Oporto, Universidade Portucalense.

Oliveira, José Augusto (20013), Na Península de Setúbal, em finais da Idade Média: organização do espaço, aproveitamento dos recursos e exercício do poder, Lisboa, Fundação Calouste Gulbenkian - Fundação para a Ciência e Tecnologia.

Oliveira, Luís Filipe (2000-2001), Em torno das casas senhoriais dos finais da Idade Média, "Media Aetas" 3/4, pp. 87-102.

Oliveira, Luis Filipe (2009), A coroa, os mestres e os comendadores. As ordens militares de Avis e Santiago (1330-1449), Algarve, Universidade do Algarve.

Oliveira, Luís Filipe (1999), A Casa dos Coutinhos: Linhagem, Espaço e Poder (1360-1452), Cascais, Ed. Patrimonia.

Pereira, Maria Teresa Lopes (2000), Alcácer do Sal na Idade Média, Lisboa, Ed. Colibri.

Rodrigues, Ana Maria (1995), Torres Vedras. A vila e o termo nos finais da Idade Média, Lisboa, Fundação Calouste Gulbenkian - Junta Nacional de Investigação Científica e Tecnológica.

Rodrigues, Ana Maria; Sá, Isabel dos Guimarães; Silva, Manuela Santos (2011-2013) (coord.) Rainhas de Portugal, Lisboa, Círculo de Leitores, 18 vols.

Silva, Manuela Santos (1997), Estruturas Urbanas e administração concelhia. Óbidos medieval, Cascais, Ed. Patrimonia. 
Silva, Maria João Branco Marques da (1991), Aveiro Medieval, Aveiro, Edições da Câmara Municipal de Aveiro.

Sousa, Armindo (1985), O discurso político dos concelhos nas Cortes de 1385, "Revista da Faculdade de Letras. História" 2, 2ª série, pp. 9-44. Sousa, Armindo, (1989), O Parlamento na época de D. João II (I. D. João II e o parlamento; II. Os Descobrimentos no parlamento), en Congresso Internacional Bartolomeu Dias e a sua época. Actas, Oporto, FLUP, vol. 1, pp. 231-261.

Sousa, Armindo (1989a), As estratégias dos municípios no reinado de D. João II, "Revista da Faculdade de Letras. História" 6, $2^{\text {a }}$ série, pp. 137174.

Sousa, Armindo (1990), As Cortes Medievais Medievais Portuguesas (13851490), 2 vols., Porto, INIC - CHUP.

Sousa, Armindo (1990a), A governação de Braga no século XV (1402-1472) (História resumida duma experiência fracassada) en IX Centenário da dedicação da Sé de Braga. Congresso Internacional. Actas, Braga, Universidade Católica Portuguesa, vol. 2, pp. 589-616.

Sousa, Armindo (1990b), O parlamento medieval - perspectivas novas, "Revista da Faculdade de Letras. História" 7, 2 $2^{\mathrm{a}}$ série, pp. 47-58.

Sousa, João Silva e (2006), A casa senhorial de do infante D. Henrique, Lisboa, Livros Horizonte.

Vasconcelos, António Maria Falcão Pestana (2008), Nobreza e Ordens Militares.Relações Sociais e de Poder (Séculos XIV a XVI), Oporto, Universidade de Porto, (tesis doctoral) URL:https://repositorio-aberto.up. pt/bitstream/10216/.../tesedoutnobrezav01000065918.pdf [consulta: $15 / 09 / 2017]$

Vicente, Maria da Graça (2012), Covilhã Medieval. O Espaço e as Gentes (Séculos XII a XV), Lisboa, Ed. Colibri.

Vieira, Cátia Manuela Rios (2011), Formas de organização social na vila de Torres Novas nos finais da Idade Média, Lisboa, FLUL (tesis de máster).

Vilar, Hermínia Vasconcelos (1988), Abrantes Medieval, Abrantes, Câmara Municipal de Abrantes.

Fecha de recepción del artículo: octubre 2017

Fecha de aceptación y versión final: abril 2108 